\title{
El existencialismo político en Martin Heidegger y Carl Schmitt
}

\section{Political Existentialism in Martin Heidegger and Carl Schmitt}

\section{Luis Alejandro Rossi*}

Universidad Nacional de Quilmes, CONICET, Argentina

\section{Resumen}

El artículo examina afinidades entre Ser y tiempo y El concepto de lo político respecto de cuestiones metodológicas, la recepción de temáticas de la filosofía de la existencia y sobre la importancia conceptual y política del concepto de "comunidad" en ambas obras. Se analiza la función metodológica que la idea de la muerte cumple en ambas teorías, señalando que ambas desembocan en un ateísmo práctico. El trabajo busca encontrar un suelo común a ambas obras que revele la ética compartida por ellas. Tanto Heidegger como Schmitt desarrollan una visión de la política como comunidad, la cual sólo es aludida en los textos a través de las imágenes de la camaradería de los soldados y la fusión nacionalista de los festejos por el inicio de la Primera Guerra Mundial. La seriedad, el riesgo y el heroísmo aparecen como los rasgos colectivos más salientes de una unión que se presenta como "destino". El estudio del pensamiento de Heidegger desde la perspectiva brindada por los conceptos del texto de Schmitt permite comprender los

* LAR: Doutor, e-mail: Irossi@unq.edu.ar 
aspectos políticos del pensamiento del filósofo antes de su compromiso con el nacionalsocialismo y permite apreciar la fuerte impronta nacionalista subyacente a algunas de sus formulaciones ontológicas.

Palabras claves: Heidegger. Martin. Schmitt. Carl. Existencialismo. Nacionalismo. Comunidad.

\section{Abstract}

The paper examines affinities between Being and Time and The Concept of the Political regarding methodological issues, the reception of themes of the philosophy of existence and the conceptual and political importance of the concept of "community" in both works. It considers the methodological function that the idea of death fulfills in both theories, pointing out that both lead to a practical atheism. The paper seeks to find a common ground for both works that reveals the ethics shared by them. Both Heidegger and Schmitt develop a vision of politics as a community, which is only referred to in the texts through the images of the comradeship of the soldiers and the nationalist fusion of the celebrations by the beginning of the First World War. Seriousness, risk and heroism appear as the most salient collective features of a union that presents itself as "destiny" The study of Heidegger's thinking from the perspective provided by the concepts of Schmitt's text allows us to understand the political aspects of the philosopher's thought before his commitment to National Socialism and allows us to appreciate the strong nationalist imprint underlying some of his ontological formulations.

Keywords: Heidegger. Martin. Schmitt. Carl. Existentialism. Nationalism. Community.

\section{Introducción}

Al examinar la relación entre la filosofía de Martin Heidegger y la política, no se puede pasar por alto que si su pensamiento posterior a 1927 más que una ruptura es una radicalización de cuestiones que ya había planteado durante la década del veinte, es justamente en estos años cuando madurará y tendrá lugar el compromiso político del 
filósofo con el nacionalsocialismo. Ello no es un accidente ni un acto oportunista, sino que esta radicalización filosófica impele a Heidegger a buscar una elucidación filosófica de la política que esté a la altura de las nuevas exigencias que cree descubrir no sólo en la situación alemana, sino también mundial. A su juicio la crisis económica y social se presenta como el signo de los desequilibrios que provocarán la ruptura definitiva con el mundo moderno, signado por el subjetivismo, el individualismo y el liberalismo. En este trabajo nos proponemos examinar algunas coincidencias entre Ser y tiempo y las ideas de Carl Schmitt en la década de 1920. Más allá de las obvias diferencias, es relevante examinar las afinidades existentes entre ambos pensadores ya desde 1927, especialmente en lo que se refiere a cuestiones metodológicas, a la recepción de temáticas de Søren Kierkegaard y a la importancia política y conceptual atribuida a la idea de comunidad, discutida apasionadamente durante la República de Weimar. En la exégesis acerca de las relaciones entre filosofía y política en Heidegger puede comprobarse un interés creciente en detectar las coincidencias de su pensamiento con posiciones como las de los "revolucionarios conservadores". Sin embargo, a pesar del antecedente del viejo libro de C. von Krockow, todavía son pocos los estudios que examinan en detalle las relaciones de su pensamiento con las ideas centrales de la filosofía política de Carl Schmitt y sólo se lo toma en cuenta a partir del compromiso político de 1933. La razón principal de esta ausencia es fácilmente discernible: buscar la relación de la primera filosofía heideggeriana con la política implica examinar su contexto histórico, social y político, lo cual, a su vez, remite a su relación con la filosofía de la existencia. Por más que Heidegger se cuidó de tomar distancia de ella después de 1945, fue la matriz que orientó a gran parte de la exégesis sobre Heidegger, especialmente la de Ser y tiempo, hasta que el ocaso y definitivo agotamiento del existencialismo fue apagando el interés por las problemáticas que le eran características. En otros términos, desde mediados de los años sesentas el desarrollo de la deconstrucción y la hermenéutica dio una nueva actualidad al pensamiento de Heidegger llevando al primer plano las temáticas ligadas al signo y al lenguaje y dejando de lado las cuestiones antropológicas. Sin embargo, al reinsertar a Ser y tiempo en 
su contexto histórico y cultural, el intérprete se ve obligado a examinar la recepción del pensamiento de Kierkegaard y el desarrollo de la antropología filosófica en esos mismos años. Se ha afirmado que entre las razones que llevan a Carl Schmitt al radicalismo político se encuentra su concepto "existencial" de la política, lo cual nos pone ante una paradoja, porque era esa misma filosofía de la existencia la que permitía una interpretación del pensamiento de Heidegger que, al hacer hincapié en las cuestiones antropológicas y en el problema de la singularización del Dasein, abordaba la historicidad a partir de una perspectiva radicalmente individual y con ello la despolitizaba, neutralizando las valencias que lo acercaban al nacionalismo, y permitía su recepción posterior por las diversas variantes del "pensamiento crítico", como vino ocurriendo hasta el presente. Si el pensamiento de Schmitt es un "existencialismo político", en el caso de Heidegger la filosofía de la existencia justificaba el supuesto apoliticismo del autor antes de 1933.

En este trabajo examinaremos las posibles relaciones que pueden trazarse entre las ideas de Heidegger y las de Carl Schmitt durante la década de 1920 en relación con la filosofía de la existencia. Para ello partiremos del planteamiento que el jurista lleva a cabo para determinar la naturaleza de lo político y consideraremos las correspondencias temáticas entre los escritos de Schmitt de ese entonces y Ser y tiempo con el fin de establecer las implicaciones políticas en su pensamiento. Usualmente se sostiene que esta cuestión consistiría en la crítica de la modernidad política por parte del filósofo de Messkirch. Creemos que Ser y tiempo trasluce una orientación nacionalista análoga a la que se encuentra en El concepto de lo político. Nos interesa este período precisamente porque es anterior al compromiso político de ambos con el nacionalsocialismo a partir de 1933. Aunque es evidente que no se podría calificar a Heidegger de filósofo político en el sentido corriente del término, es posible percibir en sus textos una búsqueda del ámbito en el cual la política se manifiesta y las ideas de Schmitt pueden funcionar como una lente para encontrar los aspectos políticos de esa filosofía. Además hay que agregar que uno de los rasgos más característicos del pensamiento de Schmitt, en contraste con otros teóricos políticos de ese momento, es su interés por elucidar los marcos de sentido 
presupuestos por el pensamiento político de una época determinada, lo cual lo acerca al modo en que Heidegger comprendió el trabajo hermenéutico, sobre todo desde mediados de los años treinta. Para poder examinar ambos textos en paralelo, realizaremos un enfoque cercano a la historia cultural, centrándonos en la problemática relativa al concepto de comunidad y a su conformación.

\section{Afinidades metodológicas y temáticas entre Heidegger y Schmitt}

Si comenzamos nuestro examen a partir de la metodología empleada por ambos pensadores, notaremos que hay una fuerte impronta del vitalismo, por lo que la ambición de atenerse a la facticidad redunda en la naturaleza misma de la investigación emprendida. Tanto Schmitt como Heidegger elaboran un discurso que pretende para sí un carácter formal: Heidegger afirma por una parte que es característico del discurso ontológico una "peculiar formalidad y vacuidad" (HEIDEGGER, 1976, p. 330), pero la interpretación ontológica necesariamente supone un tener previo, un ver previo y un concebir previo, cuyo conjunto configura la situación hermenéutica. Schmitt, por su parte, reivindica el carácter científico y puramente cognoscitivo de su reflexión acerca de lo político, pero reconoce que todos los conceptos políticos tienen una impronta polémica y no pueden ser comprendidos fuera de la disputa en la que explícita o implícitamente intervienen, lo que los vuelve inevitablemente situados. Tanto para Heidegger como para Schmitt hay que dar por sentado un saber previo y una implantación concreta del intérprete que imposibilita cualquier tipo de conocimiento objetivizador. Ello prueba que el formalismo con que ambos definen sus propios discursos parece ser más una concesión a la todavía vigente concepción de la ciencia como "libre de valores" que un rasgo concreto de sus respectivas construcciones teóricas. $\mathrm{Si}$, por el contrario, aceptáramos esas declaraciones de neutralidad que aparecen en sus textos, pasaríamos por alto el carácter de intervenciones políticas que ellos tienen, es decir, su propio talante polémico. 
Toda reflexión acerca de la cuestión política en Ser y tiempo tiene que enfrentar una dificultad básica: en esta obra no se tratan temas como los del poder, el Estado o la justicia, por tanto, es necesario reconocer que incluso si se alcanza una perspectiva que permita el examen de la política en ella, no se podría pretender que ese enfoque otorgaría una clave de lectura integral, sino que de todos modos ella seguiría siendo subsidiaria de otras problemáticas bajo cuya advocación la obra se presenta. No obstante, esta apoliticidad aparentemente palmaria fue cuestionada ya desde el fin de la Segunda Guerra Mundial y diversos polemistas le reprocharon a Heidegger que su filosofía tenía implicaciones ideológicas, discusión que se repitió varias veces hasta el presente. Esta recurrencia permite suponer que en sus obras había alegatos políticos disimulados, por más que no se ocuparan de la política de modo sistemático. El problema se torna más difícil si recordamos que la separación que Heidegger establece entre el dominio óntico y el ontológico condena de antemano a la ética y a la filosofía política como discursos derivados respecto de la ontología. Tampoco debemos olvidar que la naturaleza del discurso ontológico es interpretativa, pues describe el sentido de ser que el Dasein "preontológicamente" ya sabe, pero no ha explicitado. Con ello Heidegger indica lo que entiende como el carácter formal y vacuo de ese discurso: la filosofía es hermenéutica de la facticidad del Dasein. Esta voluntad de atenerse exclusivamente a lo que la facticidad muestre dificulta cualquier tipo de reflexión práctica, pues toda esfera normativa queda excluida de antemano de la dimensión originaria del Dasein. Sin embargo, el antagonismo entre comprensión propia e impropia del Dasein, el cual es uno de los ejes que articula el libro, recibe un contenido ético concreto en la medida en que la modalización propia es la determinación del Dasein resuelto que asume su finitud.

Heidegger parte de la facticidad del Dasein cotidiano en su "ser en el mundo" y conviviendo con otros. El ser del Dasein es "en cada caso mío", de donde surge la exigencia de hacerse cargo de él, porque su meta es la singularización. El Dasein es siempre "ser con", por tanto no puede existir de forma no referencial y los otros siempre están presupuestos. En la cotidianidad el Dasein está "caído" y su "ser con 
otros" no es más que "ser uno con otro": su extrañamiento respecto de sí mismo es máximo. No sólo el Dasein se comprende a sí mismo como si fuese una cosa, lo que implica la asunción de que los lazos con los otros deben establecerse como si se tratara de una sustancia que sale de sí, sino que tampoco comprende adecuadamente el fenómeno de su cotidianidad, en la cual no es "él mismo". En el ámbito de la convivencia cotidiana nunca se alcanza un verdadero "nosotros", predominan la distancia y la reserva y tampoco puede ser verdadera la unión que resulta del ocuparse de la misma cosa, la cual se alimenta con frecuencia de la desconfianza y no se da como una solicitud liberadora, dice Heidegger en una alusión apenas velada a los sindicatos obreros (HEIDEGGER, 1976, p. 163). De allí que en el marco de la convivencia cotidiana el ideal revolucionario de la fraternidad no sea más que "locuaces fraternizaciones" (HEIDEGGER, 1976, p. 395). A través del temple de ánimo señalado que es la angustia, el Dasein sacude los lazos cotidianos e inicia la recuperación de su "poder ser" íntegro. Comprende que el sentido de su ser es la temporalidad, la cual es también condición de la historicidad, la estructura de ser del Dasein que posibilita una historia del mundo y la pertenencia a ella. Pero con el acontecer del "ser con" propio trascendemos la singularidad del Dasein. Esta recuperación del ser propio se da como una resolución capaz de anticipar la propia muerte, es decir, de comprender sus posibilidades a partir de la nulidad de toda posibilidad. Heidegger afirma que el Dasein resuelto "voca" a otros a empuñar su sí mismo, su propio ser. De esta vocación y resolución se llega al acontecer de la comunidad del pueblo. Sin embargo, esa vocación de los otros Dasein no puede tener carácter mimético, ${ }^{1}$ ya que recupera en ella su singularidad. De este recorrido, sin embargo, se desprenden simultáneamente dos direcciones antagónicas: la tendencia a la singularización del Dasein (que implica diferenciación) y la tendencia a conformar una "unión verdadera" una vez que se ha dejado atrás el extrañamiento cotidiano. Respecto de su concepción de la historicidad, Ser y tiempo tiene una conclusión que es

1 Con todo, Heidegger reconoce en Ser y tiempo que la ontología fundamental se basa en un ideal fáctico del Dasein y que éste, en lugar de ser negado, debía ser comprendido en su positiva necesidad (HEIDEGGER, 1976, p. 411). 
de orden político, pero derivada de la misma ontología del Dasein. En consecuencia, la obra implícitamente entrega una fenomenología de lo político a través del esclarecimiento del encuentro del Dasein con su semejante, que Heidegger describe como su carácter "conal" (mithaften), pues el otro Dasein ya está con él antes de toda separabilidad de los sujetos.

Por su parte, "pueblo" es el nombre que en Ser y tiempo se da al acontecer de la comunidad. Por el contrario, la solicitud liberadora, el "común entregarse a una misma causa" no puede entenderse como un agregado mecánico de individuos. La resolución precursora realiza la elección "que libera para el seguimiento combatiente y para la fidelidad a lo repetible". Se renuncia a la comodidad y a las infinitas posibilidades de bienestar, es decir, a la vida burguesa y urbana, para reencontrarse en la simplicidad de un destino que se revela como colectivo. "Con esta expresión - dice Heidegger refiriéndose al destino común - designamos el acontecer de la comunidad" (HEIDEGGER, 1976, p. 508). Es claro que esta comunidad tiene un carácter nacional, ya que la unión que tiene lugar en ella no reconoce divisiones de clase y se presenta como comunidad de destino. Con todo, no se debe suponer que el acontecer de la unidad política o del pueblo como "comunidad" pueda ser despachado rápidamente como un anhelo de restauración conservadora. Durante la república de Weimar el reclamo de "comunidad" expresó un radicalismo sociopolítico que si bien se presentaba en un arco que abarcaba grupos diversos, formaba un compacto frente antirrepublicano tanto en el plano político como en el de la cultura ${ }^{2}$.

El hecho de la afirmación literal de Heidegger sea que el acontecer del "ser con" propio es "el acontecer de la comunidad, del pueblo", disimula que el uso de ambos términos asociados tiene su significado pleno en la expresión "comunidad del pueblo" (Volksgemeinschaft), que en los debates políticos de la Alemania de Weimar estaba cargada de significación política. Por tanto, si buscamos un punto de vista que descubra una dimensión política en Ser y tiempo, lo hallaremos ante todo en

2 Ya en 1924 Helmuth Plessner había dirigido una aguda crítica contra este radicalismo sociopolítico con su obra Grenzen der Gemeinschaft, en la que sostenía que "la comunidad es el ídolo de esta época" (PLESSNER, 2002, p. 28). 
el "ser con" y sus modalidades: "caída", en la cotidianidad, y "propia" cuando se da la relación entre historicidad y comunidad. Así como el Dasein recupera su "poder ser" íntegro, es decir, su potencia, en la existencia propia, en la concepción sobre la historicidad expuesta en Ser y tiempo una sociedad recupera su "poder ser" íntegro llegando a ser una comunidad, abandonando un modo de vida impersonal y atomizado para alcanzar una verdadera unidad. Aunque Ser y tiempo no indica cuáles son las características de esa comunidad, pues la cuestión no es tratada sistemáticamente en la obra, se alude a ella en varios pasajes, en la medida en que es contrapuesta a la cotidianidad "caída", en la cual su modo de convivencia es opuesto al de la comunidad futura. La elucidación de ese ámbito compartido le permite alcanzar la dimensión política, que se presenta como un examen de la esfera pública cuyo sentido, recordemos, está ligado de modo inmediato al ser en el mundo del Dasein, y no por una reflexión acerca del Estado o del poder, que serían, en todo caso, parte de una ontología regional. Esta restricción, derivada de la distinción entre lo óntico y lo ontológico, necesariamente limita la comprensión de la política a una dimensión esencial, que es una proyección de la ontología del Dasein y abandona cualquier otra faceta que implique dominación o subordinación institucionalizada (es decir, los fenómenos asociados normalmente con la política), los cuales quedan subsumidos en el plano de lo óntico.

El Dasein asume su historicidad como reiteración expresa de la tradición y de las posibilidades heredadas en ella, lo que acontece como destino colectivo. Ello se funda en el proyectarse resuelto que, libre para su muerte, da al Dasein su meta pura y lo lleva ante la simplicidad de un destino. A través de la presentación de la convivencia cotidiana y de la estructura ontológica del "uno" lo público recibe en Ser y tiempo una aproximación masivamente crítica, por el contrario, en la constitución de la historicidad acontece una posibilidad que está cerrada para la convivencia cotidiana: la solicitud liberadora que abre a una nueva convivencia, la comunidad del pueblo. Sin embargo, el acontecer del pueblo se presenta mediado por dos términos de los cuales Heidegger no lleva a cabo una elucidación fenomenológica, sino que los da por sentados: el de "generación" y el de "lucha". El pasado 
del Dasein, afirma Heidegger, es siempre el pasado de su generación (HEIDEGGER, 1976, p. 27). En Ser y tiempo no se expone por qué ello habría de ser así, dando por supuesto que la coincidencia fáctica de las edades remitiría a posibilidades comunes. Pero la importancia del concepto "generación" dentro de la argumentación reside en que ella es el sujeto de la lucha, y por ella y la camaradería que le es conexa es donde se abre el "destino colectivo". Mientras que la solicitud "sustitutivo-dominadora" ligada a la convivencia cotidiana sólo encuentra una forma de agrupamiento mecánica, la de la sociedad, ya que en ella predomina la desconfianza y la reserva, la generación hace posible el acontecer original del Dasein resuelto, colmando el hiato existente entre el destino individual y el colectivo. Pero ello se realiza, afirma Heidegger, en la lucha. A diferencia de Schmitt, quien explica que la lucha a la que hace referencia es real e implica el riesgo de la aniquilación física y que, en última instancia, considera a la lucha como una invariante antropológica en virtud de su aceptación de la antropología hobbesiana, Heidegger no elucida ni el carácter concreto de esta lucha ni tampoco contra quién está dirigida, salvo el hecho de sobreentender que combate la impropiedad. Al establecer como sujeto de la lucha a una generación de la cual no se da otra referencia, da por sentada una semejanza etaria, lo que a su vez remitiría a agrupamientos donde ello sea un requisito, pero en concreto no va más allá, quedando el término sin elucidar tanto en el plano fenoménico como en el ontológico ${ }^{3}$, pues no expone cómo se relacionaría la lucha con los modos de la solicitud y tampoco se plantea el problema de si fue elucidada correctamente desde el punto de vista fenomenológico, ya que, como forma de solicitud no podría ser remitida a ninguno de los dos polos de la solicitud expuestos en Ser y tiempo ${ }^{4}$.

3 Como recuerdan algunos críticos de Heidegger, en Ser y tiempo hay implícito un ideal existencial patético y heroico, del cual el soldado del frente de la Primera Guerra Mundial ofrecía un buen ejemplo generacional. Asimismo, no puede perderse de vista la relación de este término con la "resolución" tratada por Heidegger en los parágrafos 61 al 66 de esa obra.

4 La referencia de Heidegger a la necesidad esencial del Dasein de apropiarse de lo ya descubierto en lucha contra la apariencia y la disimulación (HEIDEGGER, 1976, p. 294) cambia el sentido con que se usa el término en el § 74 . En nuestro trabajo "El problema de la comunidad en Ser y tiempo" (ROSSI, 2016) hemos estudiado cómo Heidegger homologa los polos de la solicitud con los conceptos "comunidad" y "sociedad" acuñados por Ferdinand Tönnies. Max Weber observaba críticamente 
Schmitt utiliza de manera idiosincrásica la expresión "lo político", distinguiéndola de la política sin más. La diferencia entre ambos conceptos es la que existe entre lo instituyente y lo instituido. Lo político está ligado a la excepcionalidad, la política a la normalidad. Lo político rompe con las constricciones impuestas por la situación, mientras que la política se somete a los condicionamientos de la rutina. Lo político es simultáneamente decisión y destino, pues su carácter es existencial. Pero es decisión y destino de un pueblo. Lo político está ligado a lo público y se expresa en la decisión soberana. Por medio de ella un pueblo acepta los riesgos de la existencia política. El pueblo que no esté a la altura de esa decisión y que abdique de lo político comprobará que otros toman esa decisión por él, por ello lo político es destino.

De esta breve reseña se desprende que para Schmitt lo político es prácticamente sinónimo de la movilidad de la vida humana, una especie de "pretérito a priori", el horizonte a partir del cual las restantes actividades humanas cobran sentido, pues suponen lo político como su condición; ello le da un carácter totalizador, es la realidad que el ser humano no puede trascender. Schmitt lo identifica con el momento excepcional en que surge un nuevo orden: la alternativa a lo político no es lo impolítico, sino la destrucción mutua a través del conflicto; lo político acontece en la pacificación, siempre provisoria; también por eso el jurista distingue a lo político del Estado, pues éste no puede monopolizarlo, ya que todo orden lleva consigo la posibilidad de que lo político acontezca nuevamente. Hobbes ha descrito de manera desprejuiciada la facticidad del ser humano: toda concepción que suponga una sociabilidad natural del hombre o su inocencia inicial, como es el caso de Aristóteles o de Rousseau, niegan lo político, precisamente porque o no perciben la autonomía y especificidad de la política o suponen que ella es un mero suplemento y, llegado el caso, los seres humanos podrían desarrollar sus vidas sin ella. El conflicto, por tanto, es raigal y no necesita de un contenido concreto, pues lo político tiene lugar como

que Tönnies, al postular los conceptos de "comunidad" y de "sociedad" como formas de asociación derivadas de formas genéricas de relación entre los seres humanos, desarrollaba una concepción puramente estática de los agrupamientos humanos, ya que no tomaba en cuenta al conflicto como forma de relación. Lo mismo ocurre en relación con la "lucha" planteada en Ser y tiempo respecto de los polos de la solicitud expuestos en esa misma obra. 
intensificación de cualquier disputa y no exclusivamente de aquellas que conciernen a la conquista del poder. Por esta razón lo político tiene lugar como declaración de enemistad, como la decisión que excluye y limita: la determinación de un enemigo, el cual amenaza existencialmente una forma de vida concreta. El enemigo no tiene un contenido específico que lo vuelva tal, no hay una enemistad natural, sino que es a la inversa, es enemigo aquél que puede ser objeto de una declaración de enemistad, pues implica la posibilidad de un conflicto existencial, es decir, armado. La comunidad política, el Estado, se deriva de la agrupación originaria que es el resultado de la decisión soberana, de la declaración que separa amigos y enemigos. La lucha concreta tiene así un sentido originario (y "lucha" debe entenderse como hostilidad concreta y material). El carácter trágico de lo político está dado por la imposibilidad de eliminar esta hostilidad, lo político implica siempre, aunque sea remotamente, la posibilidad de la muerte, de otro modo, el concepto de enemigo perdería todo significado concreto.

Tanto para Heidegger como para Schmitt, el objetivo es alcanzar una comprensión que evite una sustancialización del objeto de estudio. Ello los lleva a dar una primacía a la posibilidad por sobre la realidad. El Dasein es esencialmente "poder ser", por eso no puede comprenderse como una cosa meramente presente, dice Heidegger. En Schmitt la posibilidad se presenta como aquello que define al enemigo. Una vez que lo político no puede ser identificado sin más con el Estado y que éste sólo puede ser entendido como la situación de un pueblo, la posibilidad de que cualquier otro devenga enemigo está siempre latente y de ello se deriva una contingencia radical de los hechos con los que hay que enfrentarse en la política, los cuales no pueden ser deducidos de ningún esquema teleológico. De ello se sigue que el punto de mayor significación política en Ser y tiempo, la exposición del acontecer del pueblo, muestra analogías significativas con el planteo de Schmitt acerca de lo político. En ambos autores el acontecer del pueblo queda asociado al destino, a la lucha y a la posibilidad de la muerte. Este acontecimiento es una decisión disruptiva, pero para que devenga historia, ni ella ni el destino pueden ser concebidos de un modo atomístico. Ello se vuelve más claro si se atiende a que tanto Heidegger como Schmitt 
exponen el instante de la fundación, la irrupción de una nueva identidad. Mientras que para el jurista lo político es el horizonte bajo el cual ella tiene lugar, el filósofo ve en la historicidad el horizonte irrebasable. Desde perspectivas diferentes exponen el acontecer de lo excepcional, de lo que se muestra como originario. La fundación no consiste en un pasaje definitivo a otro estadio, como si se tratara de un esquema evolucionista, sino que el carácter originario de lo acontecido debe ser custodiado y mantenido, ya que lo excepcional no está asegurado. Es en este punto donde se apoya la analogía que trazamos entre la irrupción de lo político y la constitución de la historicidad. Ninguno de los dos son conquistas definitivas, sino que están amenazadas. Por una parte, el Dasein, incluso el propio, es siempre cadente y se pierde y dispersa, por otra, no hay modo en que la comunidad política surgida de la decisión soberana pueda impedir que el fantasma del estado de naturaleza, esto es, la guerra civil, la acompañe. En el caso de Heidegger lo histórico tiene lugar arrancándolo de la rutina, expresada en el "uno". En lo que concierne a Schmitt la decisión soberana tiene lugar en un vacío normativo, cuando ocurre aquello imprevisible para la mecánica de la norma, de modo análogo al milagro en el plano teológico.

\section{El individuo y la comunidad}

Ni Heidegger ni Schmitt podrían ser catalogados como individualistas. Ambos rechazan la idea de un individuo atómico que exista de modo no referencial y cuyas asociaciones más o menos voluntarias originarían la sociedad. Sin embargo, el hecho de que ambos partan de lo excepcional vuelve al individualismo un problema para la propia construcción teórica. En el caso de Schmitt, su aceptación de la antropología hobbesiana lo obliga, si no quiere volver a caer en un atomismo sociológico y político, a dejar de lado el elemento pactista de la construcción hobbesiana, que es el que expresa en forma más acabada el individualismo. Su objetivo es recuperar el principio de que todo orden político se funda en un intercambio entre protección y obediencia, lo que le permite acentuar el decisionismo de Hobbes, quien, por el 
contrario, lo moderaba mediante un sistema de leyes naturales. Como el propio Schmitt reconocerá en el prólogo de 1933 a Teología política, este énfasis en la decisión frente a la generalidad de la norma lo conduce a postular un decisionismo que tiende siempre a la arbitrariedad, al no poder relacionar la decisión con un orden concreto, por tanto, al hacer de Hobbes el modelo puro del pensador decisionista, Schmitt debe expurgar del pensamiento del filósofo inglés todos aquellos elementos que permitan reconducirlo al individualismo en su forma moderna, del cual, sin dudas, Hobbes es el iniciador.

El individualismo se presenta en la hermenéutica del Dasein a través de la recuperación de su sí mismo que le ha sido arrebatado, la cual, si bien realizaría su singularización, conlleva el riesgo de un "solipsismo existencial", preanunciado en la angustia, y que en el plano político se traduciría en una nueva forma de individualismo antes que en la conformación de una comunidad. Ya hemos indicado el papel que cumple la generación respecto de la solicitud liberadora. Para expresar en una fórmula lo que hemos expuesto, digamos que si la existencia propia es el "poder ser" del Dasein, la comunidad propia o "ser con" propio es el "poder ser" del pueblo y ése es el mensaje político de Ser y tiempo. Sin embargo, la recepción de elementos del pensamiento de Kierkegaard, sobre todo el énfasis no sólo en la facticidad del Dasein, sino también en su carácter radicalmente singular, produce este hiato entre ambos polos. Entre el Dasein que asume propiamente su existencia (y que lo hace, recordémoslo, en forma aislada, sin ayuda o colaboración de los demás) y el "ser con" propio, el cual es, de acuerdo a Heidegger, la "verdadera unión", no hay más mediación que la lucha y la generación. Es precisamente este aspecto singularizador originado en la filosofía de la existencia el que permitirá las lecturas de Ser y tiempo como texto apolítico que se hicieron durante más de medio siglo, ya que la conquista de la propiedad era interpretada a partir del aislamiento de la angustia y luego de la singularidad de la existencia propia, quedando de lado la cuestión de la historicidad como una incógnita no del todo resuelta en la obra, sobre todo por la insistencia por parte de Heidegger acerca de que las modalizaciones del Dasein, tanto la propia como la impropia están ligadas a su resolución y, en consecuencia, no 
implican ninguna dimensión práctica propiamente dicha, o, a lo sumo, como ocurrió para la mayoría de los intérpretes que siguieron esa línea, se trataría de una ética individualista y de la diferenciación, carente de toda connotación política. En forma análoga a lo que ocurre en la reflexión schmittiana, que abandona el decisionismo para emprender un examen de los órdenes concretos del derecho, la profundización por parte de Heidegger de la constitución de lo histórico en los años treinta responde a esta problemática que en Ser y tiempo permanece afectada por el hiato existente entre el carácter singular del Dasein que empuña su ser desde su Jemeinigkeit y el "nosotros" que acontece como pueblo.

Tanto para Schmitt como para Heidegger, la decisión es capaz de romper con todos los lazos heredados y con todo determinismo, el cual queda recluido en el mundo de la regla y de la normalidad. De la filosofía de la existencia resulta esta afirmación de la libertad humana que expresa una movilidad superadora de cualquier limitación a priori que se le quiera imponer, Si bien Heidegger o Schmitt son críticos del individualismo radical que esta libertad supone, sus reelaboraciones de esta idea llevan a que la decisión se confunda con el voluntarismo. Schmitt sostiene que lo político posee un primado respecto de cualquier otra actividad humana por su capacidad de aglutinación, es decir, por ser el tipo de unión que alcanza mayor intensidad, lo que encuentra su reflejo en la comunidad propia anhelada por Heidegger, la cual es capaz de romper con los automatismos cotidianos y su impersonalidad. Tanto lo político como la comunidad propia implican una nueva forma de sociedad, de la cual ambos autores no dan explicaciones concretas, sino solo aluden a ella bajo la idea de comunidad.

Este radicalismo de la voluntad acercará a ambos a las ideas de las agrupaciones antirrepublicanas extremas a través del modelo político implícito en sus textos y con el cual comprenden ese "nosotros". Tanto Heidegger como Schmitt rechazan la sociedad entendida como una formación mecánica y el pluralismo de fines que le es connatural en favor de lo que ven como una renovación social. Esta afirmación podría moderarse sosteniendo que ambos pensadores quieren articular conceptualmente el punto inicial de toda agrupación política, el momento de la unanimidad, a la cual imaginan bajo la forma de la comunidad y 
cuyo acontecer se da como un hecho excepcional. No es casual que el carácter revelador de la excepción se presenta en ambos como la posibilidad de descubrir una contraposición entre una realidad "impropia" y otra "propia", una normalidad "agarrotada" por la rutina y la banalidad y una excepción que revela la verdadera estructura de lo real, volviéndose así la fascinación por la excepción, más que un rechazo a una vida rutinaria, una protesta contra la normalidad de la vida normal, según la eficaz expresión de W. Franzen (FRANZEN, 1989, p. 85). El concepto de lo político lo enuncia del siguiente modo: "en realidad no existe ninguna «sociedad» o «asociación» política, sino sólo una unidad política, una «comunidad» política. La posibilidad real del reagrupamiento de amigo y enemigo es suficiente para constituir, por encima del simple dato asociativo-social, una unidad decisiva que es algo específicamente diverso y decisivo respecto de las demás asociaciones." (SCHMITT, 1996b, p. 45). Dicho en otros términos: lo político, el cual, recordemos, no puede identificarse con el Estado, sólo puede realizarse en una comunidad, la sociedad como forma de agrupamiento carece de la unidad intensiva que permite el enfrentamiento entre amigo y enemigo. Schmitt ejemplifica su afirmación por medio del recuerdo del estallido de la Gran Guerra. "El día de la movilización la sociedad que había existido hasta entonces se transformó en una comunidad", señalando a la nación en armas como el paradigma de la comunidad.

Estas convergencias entre los textos de Schmitt y los de Heidegger antes de 1933 muestran que entre la Entscheidung schmittiana y la Entschlossenheit heideggeriana hay fuertes correspondencias. Con todo, hay una diferencia significativa, que no alcanza para considerar sus posiciones como antagónicas, pero que marca una divergencia que se profundizará con el tiempo: la atención de Heidegger está dirigida a las condiciones que posibilitan el acontecer de una identidad histórica, mientras que la de Schmitt busca elucidar las condiciones que posibilitan la fundación de un orden político. Ambas cuestiones no son excluyentes. No puede haber un orden político sin identidad (Schmitt afirma que la identidad y la representación son los principios formales de todo orden político) y una identidad histórica no puede perdurar sin darse un orden, cuya naturaleza tiene que ser ante todo política. No 
obstante, la reflexión heideggeriana pasará siempre por alto el carácter representativo de la decisión teorizada por Schmitt. En la reelaboración de la noción de soberanía a través del concepto de "lo político", el jurista hace retornar al primer plano el concepto de Estado. Por tanto, la comunidad mentada por Schmitt irrumpe espontáneamente y como un acontecimiento, pero debe encontrar alguna forma de institucionalización. El eje horizontal de la identidad no puede, por sí mismo, constituir nada sin el eje vertical de la decisión representativa.

Esa misma sociedad que el jurista consideraba afectada por una deriva centrífuga a la que sólo se podía poner coto por medio de lo político, es observada por el filósofo bajo el signo de la uniformidad y el aplanamiento. En donde Schmitt ve levantarse el fantasma de la disolución progresiva que a través de la competencia entre los grupos lleva a la guerra civil, Heidegger halla que el fenómeno de la convivencia o "ser uno con otro", por detrás de esa aparente y caótica diversidad de fines, está atravesado por un consenso que no es advertido por el Dasein, pero que resulta eficaz a la hora de dar una tonalidad homogénea a la sociedad. Esta diferencia respecto del diagnóstico acerca de la sociedad presente es fundamental para comprender la discrepancia entre ambos en los años posteriores. Mientras que Schmitt anhela el establecimiento de una comunidad para poner un dique a un pluralismo al que ve alimentando una heterogeneidad creciente, lo cual pone en peligro a la unidad política, Heidegger ansía llegar a una comunidad popular a través de la asunción de un destino colectivo elegido por el Dasein como su singularización más propia. A diferencia de Schmitt, cuyo interlocutor polémico es el campo de la jurisprudencia, la discusión de Heidegger sobre la uniformización y aplanamiento de la sociedad está enraizada en las construcciones de la teoría social alemana (en especial en las perspectivas de Ferdinand Tönnies y Georg Simmel), la cual, a su vez, encuentra un antecedente remoto en el pensamiento político de Alexis de Tocqueville y su teorización de la "tiranía de la mayoría" operante en las democracias modernas. Pero a diferencia del pensador francés, que se pregunta cuál será el destino de la libertad del individuo en las sociedades modernas, Heidegger se pregunta por las posibilidades más propias del ser humano entendido como Dasein, 
lo que significa en el plano histórico-político ser miembro de una comunidad de nuevo tipo. De todo ello podemos deducir que si Schmitt es un pensador paradigmático del realismo político, lo que no por casualidad lo acerca al conservadurismo, el hecho de que Heidegger busque dar una implantación social a su pensamiento no se traduce en ninguna forma de realismo político, sino más bien en una reflexión sobre lo político centrada en el acontecer del pueblo como fundación de una identidad, la cual solo se realiza como revolución. De allí que el fenómeno del poder político aparezca siempre en un segundo plano en sus análisis, mientras que inevitablemente ocupa el centro en los del jurista, divergencia sobre la que reflexionará Heidegger años después contraponiendo la política como imperium y mando frente a lo político entendido a partir de la polis. A la inversa, no habrá nada equivalente a la búsqueda de la identidad del Volk alemán en los escritos de Schmitt.

No obstante las diferencias respecto del momento institucional, no puede pasarse por alto que la finalidad básica de la política presentada tanto por El concepto de lo político como por Ser y tiempo es la de liberación. Aunque una intérprete como Barbara Merker sostenga que el primer Heidegger transforma el modelo husserliano de la reflexión en uno de la conversión, ello sería válido si dejamos de lado la problemática del acontecer del pueblo, cuya historicidad se conforma como una liberación. Aunque pueda asociarse toda conversión con una liberación, en el caso que nos ocupa, al estar unida a la conformación de la comunidad, la liberación de la impropiedad adquiere un sentido político inmediato que no está presente en la idea de conversión, la cual permanece en un plano puramente individual. En los años inmediatamente posteriores Heidegger utilizará cada vez más la expresión "autoafirmación" para referirse a esa meta del "ser con" propio. Los textos de Schmitt en estos años también están fuertemente marcados por la idea de autoafirmación. Si el universo internacional de los Estados está afectado por el pluralismo por su misma conformación, y por eso es en realidad un pluriverso, ello implica, a su juicio, que al interior de la comunidad política se dé necesariamente un universo, lo que significa la supresión del pluralismo, de modo que sea contrarrestada la deriva 
a la que toda sociedad tendería. Sólo así la unidad política estará en condiciones de afrontar los riesgos de la existencia política en el plano internacional. Por caminos diferentes, tanto Heidegger como Schmitt encuentran problemático al pluralismo sociopolítico y buscan ponerle un dique: el filósofo busca una comunidad en la que acontezca la unidad del pueblo a través de un propósito común, el jurista, por su parte, supone que sólo el poder político, a través de su capacidad de mando, puede brindar esa unidad y a la cual la sociedad no podría llegar de manera espontánea. Esta divergencia respecto de la capacidad de la sociedad para darse un orden a sí misma es lo que separa de manera más profunda a los planteos de Heidegger y de Schmitt.

\section{La lucha como problema}

Schmitt sentía una profunda repulsión por las ideas de los hermanos Friedrich y August Schlegel y las de Adam Müller, los escritores contrarrevolucionarios alemanes de principios del siglo XIX. En Romanticismo Político ironizaba acerca de la concepción que Müller tenía acerca de las oposiciones en lucha. Rechazaba como vacua la exaltación retórica de la pugna y de la guerra entendida al modo de los románticos, señalando que en la obra de este autor podían estar en contienda las realidades más diversas y mostrando cómo esta concepción alcanzaba el grotesco al presentar como especies de la lucha en un mismo nivel las disputas interestatales y el trabajo del zapatero con el cuero (SCHMITT, 1925, p. 191-192). En El concepto de lo político, Schmitt vuelve sobre el tema al precisar los significados de "guerra" y de "lucha". Como es sabido, su objetivo es diferenciar el sentido específico del término que va asociado a lo político de otras acepciones más generales, en las que confluyen las resonancias románticas nombradas (referidas a "la vida como lucha") junto con las concepciones liberales, en las que ese término es sinónimo de "competencia". Schmitt enfatiza el sentido originario del término, esto es, el carácter físico del posible combate con el enemigo y el hecho de que en esa eventualidad esté comprendida la posibilidad de la eliminación física y de la muerte. El 
rechazo de Schmitt hacia concepciones como las de los románticos también se apoya en que considera frívolo equiparar la actividad humana y la lucha. Quiere restituirle a este fenómeno su verdadero carácter y lo que está realmente en juego en ella. Recordemos que también para Heidegger la comunidad propia tiene lugar como producto de la lucha de la generación y ella realiza el destino colectivo, pero su referencia a la cuestión es más huidiza. El tono existencial común a los textos del filósofo y del jurista expresa un énfasis en la lucha como factum ineludible. Ambos, por vías diversas, hacen del conflicto un hecho central y buscan una concreción que implica la aceptación del conflicto como punto de partida. Habíamos señalado, además, que Schmitt afirma que los conceptos centrales de la teoría política deben entenderse en sentido polémico: ellos también están alcanzados por el conflicto, ya que forman parte de un debate y él constituye el horizonte que da sentido a esos mismos conceptos.

La posibilidad del "caso decisivo" y la irrupción de lo político son sinónimos para Schmitt. La existencia puramente privada y carente de riesgos es el ideal del burgués, la asunción de la existencia política por parte de un pueblo es afrontar una vida riesgosa y de sacrificios. Simultáneamente, lo político sólo puede ser conflicto y sólo el conflicto otorga seriedad a la vida humana. Un mundo en el que hubiera un Estado mundial equivaldría a un mundo sin política y completamente pacificado, en el que desaparecería la distinción entre amigo y enemigo y por tanto desaparecería la seriedad, que sería reemplazada por la competencia agonística (SCHMITT, 1996b, p. 54). Lo político, en última instancia, significa asumir el carácter trágico de la vida humana.

El factum de la lucha es el fundamento que tanto Schmitt como Heidegger comparten en su rechazo al arquetipo cultural del liberalismo: el burgués y el individualismo asociado con él, que reduce la lucha y los conflictos a mera competencia y discusión. Esta pasión "antiburguesa", que extiende lo "burgués" hasta límites casi irreconocibles, llevó a Leopold Schwarzschild a afirmar (refiriéndose a E. Jünger, pero también es válido para Schmitt y Heidegger) que, al fin de cuentas, burgués sería cualquiera que busque seguridad (SCHWARZSCHILD, 1983, p. 492). Frente al burgués, en sus textos son elevados el citoyen 
rousseauniano (Schmitt) y el soldado del frente, que Heidegger transforma en la existencia "propia" a través de la resolución. En este sentido, tanto Ser y tiempo como El concepto de lo político tienen un marcado carácter propositivo que desmiente su carácter puramente formal. Son una invitación a la toma de conciencia y a la lucha concreta, por eso en ambos textos "lucha" aparece ligada a "destino", "muerte", "tradición" y "forma de vida".

\section{Conclusión: la muerte, la autoafirmación y el ateísmo práctico}

Habermas señaló hace años el carácter "expresionista" de El concepto de lo político, calificación que puede extenderse a Ser y tiempo. La relación con la muerte, determinante en la articulación interna de ambas obras, le da ese aire. "Muerte" remite en ambos textos a la condición de la existencia que Heidegger designa como "facticidad", esto es, el hecho de encontrarse ya siendo y tener que ser. Pocos años antes, Max Weber había señalado el carácter trágico de la política en la subyacente relación de la muerte con el poder estatal, residiendo la razón última de la obediencia en la capacidad del Estado de ordenar la muerte tanto de sus enemigos internos como externos. Schmitt asume plenamente esta situación y podría decirse que radicaliza sus términos, pues en El concepto de lo político sostiene que no hay justificación posible de una guerra a partir de una norma. La guerra hecha en nombre de principios abstractos (sean de orden moral, social, jurídico, etc.), es un engaño, pues no habría ningún fin racional, ni un ideal social tan bello que pueda justificar que los hombres se maten recíprocamente (SCHMITT, 1996b, p. 49-50). Una declaración semejante explica descarnadamente en qué consiste en última instancia lo político, esto es, el fundamento del poder del Estado: éste puede exigir a los miembros de la comunidad política que den su vida por él, aun cuando el mismo Schmitt reconoce que no hay ningún ideal o norma que justifique morir por ellos. Así, la guerra es el hecho político por excelencia, pues implica la decisión más extrema que puede tomar el soberano, por tanto, no puede tener otra justificación que no sea política. Ello significa que el 
enemigo sólo puede ser de orden político y en ese sentido también lo es existencialmente, pues sus acciones y objetivos ponen en peligro la forma de vida propia. Una guerra, desde esta perspectiva, sólo puede justificarse como guerra defensiva: una comunidad, en caso de necesidad, se defiende físicamente del peligro que significa un enemigo. Ella misma lo declara como tal, pues ésa es la capacidad propia de la decisión y la existencia políticas. Por lo tanto, no habrá ninguna norma, ideal o legalidad que pueda justificar que los hombres se maten, pero sí lo podrá hacer un factum: la forma de vida propia de una comunidad que exige ser defendida. El carácter excepcional de la decisión aparece aquí: no hay un fundamento ulterior.

Por ello, aunque en la obra de Schmitt "muerte" refiere al carácter fáctico del poder estatal, esto es, a la eficacia de su acción protectora de la comunidad, el sentido pleno del concepto se alcanza cuando es asociado al de "enemigo". La muerte es la eventualidad a la que la lucha con el enemigo puede llevar. En lo político la muerte está en juego. Se puede trazar una analogía entre la situación en la que el Dasein se encuentra arrojado, teniendo que hacerse cargo de su existencia, y el modo en que los Estados se encuentran existiendo en un sistema interrelacionado. La situación en que éstos están implica la posibilidad del conflicto y les es imposible sustraerse a ella. De todos modos, la conformación de un Estado mundial no sería una solución y equivaldría a la despolitización, pues desaparecería la posibilidad de distinguir entre amigo y enemigo. La oposición de Schmitt a esta posibilidad es ambigua: no la rechaza exclusivamente a causa de la imposibilidad fáctica de un poder estatal planetario. Empero, va más allá: al preguntarse en qué consistiría un mundo despolitizado y pacificado, en el que la distinción amigo-enemigo ya no estuviera vigente, encuentra que habría solamente una concepción del mundo, una cultura, una civilización, una economía, una moral, un derecho, un arte, un entretenimiento, etc. libres de la política, pero ya no política ni Estado (SCHMITT, 1996b, p. 54). Leo Strauss observó que en este párrafo se deja ver la verdadera intención de Schmitt al escribir El concepto de lo político. Ella no es simplemente mostrar que el factum de lo político es un mal necesario, como podría haber sido la intención de Hobbes, ni tampoco reafirmar 
su autonomía, como Maquiavelo, sino que su objetivo principal es la afirmación de lo político. Un mundo sin política es un mundo sin seriedad y sin riesgo, un mundo donde ya no existe el "caso serio". Lo político, en consecuencia, tiene que ser acompañado por una ética específica (STRAUSS, 1988, p. 114), la cual se desprende del carácter "existencial" de lo político y del enemigo. Postular una ética propia de lo político significa para Schmitt que él es la forma de existencia propia de un pueblo. Lo político no presupone una ética, sino a la inversa: sólo a partir de la forma de existencia política puede establecerse la ética que le corresponde. Una ética semejante no podrá consistir en un sistema de normas generales ni tampoco podrá estar ligada exclusivamente a la existencia individual. En consecuencia, la ética de lo político no concierne a la forma de una acción, sino que tiene que estar vinculada con lo más peculiar de la existencia política: el riesgo. Ella es peligrosa porque es la forma de existencia opuesta al modo de vida burgués. Al contrario de la previsibilidad del mundo de la burguesía y de las garantías que ofrece el Estado de derecho, en la existencia política no hay manera de conquistar la seguridad porque el antagonismo en que ella se sostiene no puede desaparecer.

La imposibilidad de erradicar el peligro que conlleva la existencia política puede hacer retroceder a un pueblo y evitar toda posible enemistad bajo la excusa de no pretender más que una existencia pacífica. Schmitt responde que todo pueblo que no sea capaz de la decisión política y de señalar a su enemigo, encontrará otro que lo hará por él, de forma que la enemistad que se quería evitar no sólo le será impuesta, sino que también comprobará que era inevitable. Por tanto, la ética de lo político no puede ser la postulación de una paz perpetua, ni la juridización de las relaciones internacionales ni, menos todavía, el sueño de una concordia universal entre los pueblos. La ética que afirma lo político es la que no sólo asume el riesgo inevitable que implica la inexistencia de un poder mundial, sino también se niega a considerar que un poder semejante pudiera ser algo bueno. Schmitt no postula que el estado de guerra permanente sea bueno, pero rechaza que la paz perpetua lo sea. La disposición a la lucha es inseparable de la forma de existencia política, la renuncia a la lucha es la renuncia a lo político y 
a la afirmación de la propia soberanía. La ética de lo político rechaza a un pueblo débil y exige su afirmación a través del Estado nacional, el cual, en la medida en que no puede contener más que una nacionalidad, sólo puede ser homogéneo diferenciándose de otros Estados. El sueño del cosmopolitismo intenta suprimir el factum de la enemistad, que es inseparable de la existencia política, la cual, a su vez, se funda en el "pluriverso" de las naciones.

Para Heidegger la anticipación de la muerte lanza al Dasein a su finitud y le confiere su finalidad, ya que sólo su asunción plena permite alcanzar una existencia propia. Si el Dasein huye de su responsabilidad por su existencia, la delega en el "uno" y vive en la ilusión, pues cree ser libre y no hace más que obedecer. A través de la angustia y de la anticipación resuelta de la muerte Heidegger busca una singularización de la que resulta una situación paradójica, pues reconoce que la angustia lleva a un solipsismo existenciario, pero que en términos existenciales ella no produce la instalación de una cosa-sujeto aislada de su mundo, sino que pone al Dasein ante sí mismo y lo "abre" a su "ser en el mundo".

Por todo ello, y si además recordamos la mención del propio Heidegger al "ideal fáctico" que guía la ontología fundamental, así como la importancia de la lucha de la generación, es claro que la anticipación resuelta de la muerte, de la que surge la comunidad y el destino común, presenta en términos ontológicos el mundo de la trinchera descrito por las novelas de Ernst Jünger en los primeros años de la década de 1920. En la comunidad del frente los soldados ya se encuentran en la disposición de ánimo necesaria para que la comunidad de destino, que Heidegger caracteriza "de seguimiento combatiente" se realice. Su fenomenología de los temples de ánimo, que contrapone la angustia al miedo, logra dar forma filosófica a una situación concreta ligada al combate, a la lucha y a las trincheras. Las descripciones del combate de Jünger y su exaltación de la figura del héroe permiten comprender mejor el significado de que el Dasein tenga que "elegirse un héroe". La reunión de estos elementos nos permite concluir que la comunidad del pueblo que se menciona en Ser y tiempo tiene fuertes coincidencias con la comunidad de los soldados de la literatura de la Fronterlebnis; es 
verosímil interpretar al acontecer histórico del pueblo mencionado en Ser y tiempo como una transcripción de aquella en clave filosófica. La resolución frente a la posibilidad de la muerte y la lucha del Dasein con su generación por la comunidad propia expresan en términos ontológicos esta disposición a la lucha que el pueblo, al igual que en el caso de Schmitt, debe asumir.

Al llevar al primer plano la problemática de la excepción, la relación de ambas obras con los fenómenos ligados a la repetición como ser la rutina, la normalidad, y por extensión la tradición, se torna ambigua. En Ser y tiempo la tradición encubre y oculta, alejada de la experiencia originaria, se vuelve repetición deformada que impide el acceso a la palabra inicial. Paradójicamente la tradición desarraiga, pues hace olvidar el origen y la necesidad de su regreso. Pero, a diferencia de una concepción que haga tabla rasa del pasado, la destrucción de la historia de la ontología propuesta por Heidegger no quiere sepultarlo en la nada, y el regreso al pasado sólo puede ser fecundo si se da como "una productiva apropiación" (HEIDEGGER, 1976, p. 29) a través de sus posibilidades implícitas. La destrucción del estado de interpretado vigente a través de las habladurías del "uno" sigue el mismo esquema: el Dasein se apropia de su pasado mediante una modificación existencial que abre a la reiteración de las posibilidades contenidas en la herencia. Ello acontece como una modificación existencial, fáctica, de la convivencia. De la solicitud liberadora surge por primera vez un convivir propio. A pesar de que Heidegger afirma que esta resolución no puede tener un contenido a priori, sino que sólo la posibilidad del caso puede darlo (HEIDEGGER, 1976, p. 311), recordemos que las posibilidades son aquellas que pueden actualizarse en la herencia, por eso también son "destino común". La decisión soberana teorizada por Schmitt tiene lugar bajo una situación análoga: "en la excepción la fuerza de la vida real rompe la corteza de una mecánica agarrotada en la repetición" (SCHMITT, 1996a, p. 21). La decisión se desvincula de las ataduras normativas que impedían el surgimiento de una nueva ordenación. Si el pensador quiere alcanzar la facticidad y no imponerle esquemas abstractos debe atenerse a la excepción, que "se comprende a sí misma y a la regla". Lo que Lucien Jaume afirma respecto de Carl Schmitt vale 
para ambos pensadores: la decisión es "puramente concreta, en el sentido en que ella está ligada enteramente a las circunstancias $\mathrm{y}$, por tanto, no puede ser justificada refiriéndola a una norma general" (Jaume, 2004; 2). También en Heidegger hay un rechazo al normativismo ético. La comprensión de la vida humana a partir de su facticidad va unida a una repulsa a cualquier norma, la cual es juzgada como abstracta per se. Por ello, el juicio moral de una acción, al igual que en Schmitt, está ligado exclusivamente a la decisión. Ella establece el carácter moral sólo por el hecho mismo de ser decidida, no porque se adecue a alguna norma o porque exprese algún ideal. Sin embargo, la referencia de la decisión no es exclusivamente la situación concreta, pues para ambos la necesidad de la decisión y el carácter de ruptura con respecto al statu quo ante muestran su carácter fundador, por lo cual, no puede ser juzgada a partir de las normas existentes. La decisión crea una nueva realidad, la comunidad propia para Heidegger, el Estado para Schmitt.

La anticipación de la muerte tiene en ambos autores una función metodológica, pues establece el carácter de la responsabilidad propia y la soledad radical a la que un individuo y también un pueblo se enfrentan si quieren asumirla. La posibilidad irrebasable de la muerte establece el sentido de la conceptualización y el caso límite se convierte en el principio de determinación a partir del cual ambos pensadores dan significado a los fenómenos que quieren aprehender. "Muerte", entonces, significa la instancia dadora de sentido, a pesar de que ella misma aparezca como incomprensible. Pese a que tantas veces se menciona la relación de ambos autores con el catolicismo, la muerte no aparece siquiera como un enigma, pues no tiene sentido posible. Es, simplemente, el límite de la facticidad humana. No hay un sentido ni una trascendencia posibles para la muerte. La muerte da sentido, pero ella no recibe ninguno, pues es un término intemporal en ambas construcciones. Tanto para Schmitt como para Heidegger, "lucha" y "muerte" conciernen a la conquista de un sentido para la vida humana que no puede ser trascendente con respecto a ésta. Frente a las idealizaciones de los románticos, ambas obras postulan una lucha concreta en la que el riesgo de la muerte es real. Sin embargo, asumir la posibilidad concreta de la muerte no convierte a ésta en un pasaje a una forma de vida 
más alta ni un sacrificio que eleve el significado de la vida cotidiana. Ella es únicamente un acto de coraje que otorga a la existencia su sentido y su seriedad. Es esta consideración nihilista de la muerte, que disuelve toda normatividad y todo ideal, lo que fundamenta el ateísmo práctico de ambas teorías.

\section{Bibliografía}

FRANZEN, W. Die Sehnsucht nach Härte und Schwere. Über ein zum NSEngagement disponierendes Motiv in Heideggers Vorlesung Die Grundbegriffe der Metaphysik von 1929/1930. In: GETHMANN-SIEFERT A.; PÖGGELER, O. (ed.). Heidegger und die praktische Philosophie: Frankfurt: Suhrkamp, 1989. p. 78-92.

HEIDEGGER, M. Sein und Zeit. Frankfurt: Klostermann, 1976.

LUCIEN, J. "Carl Schmitt, la politique de l'inimitié". Historia Constitucional, n. 5, p. 1-9, 2004. Disponíble en: Historia Constitucional: <http://hc.rediris.es/05/ indice.html>. Acceso 20 nov. 2016.

PLESSNER, H. Grenzen der Gemeinschaft. Eine Kritik des sozialen Radikalismus. Frankfurt: Suhrkamp, 2002.

ROSSI, L. A. El problema de la comunidad en Ser y tiempo. In: LYTHGOE, E.; ROSSI, L. A. Ser y tiempo, singularización y comunidad. Buenos Aires: Biblos, 2016. p. 103-200.

SCHMITT, C. Politische Romantik. Berlin: Duncker \& Humblot, 1925.

SCHMITT, C. Politische Theologie. Berlin: Duncker \& Humblot, 1996a.

SCHMITT, C. Der Begriff des Politischen. Berlin: Duncker \& Humblot, 1996b.

SCHWARZSCHILD, L. Heroismus aus Langeweile. In: KAES, A. Weimarer Republik. Manifeste und Dokumente zur deutschen Literatur 1918-1933. Stuttgart: Metzler, J. B., 1983. 
STRAUSS, L. Anmerkungen zu Carl Schmitt, Der Begriff des Politischen, In: MEIER, H. Carl Schmitt, Leo Strauss und »Der Begriff des Politischen«. Stuttgart: Metzler, 1988.

Recebido: $14 / 03 / 2017$

Received: 03/14/2017

Aprovado: 24/07/2017

Approved: 07/24/2017 